\title{
Damage Identification of Prefabricated Reinforced Concrete Box Culvert Based on Improved Fuzzy Clustering Algorithm and Acoustic Emission Parameters
}

\author{
Yafeng Gong $\mathbb{D}^{D}$, Siyuan Lin $\mathbb{D}^{D}$, Feng He $\mathbb{D}$, Yang He $\mathbb{D}$, and Jiaxiang Song $\mathbb{C}$ \\ College of Transportation, Jilin University, Changchun 130025, China \\ Correspondence should be addressed to Feng He; hefeng@jlu.edu.cn
}

Received 23 November 2020; Revised 19 December 2020; Accepted 2 January 2021; Published 18 January 2021

Academic Editor: Yubo Jiao

Copyright (c) 2021 Yafeng Gong et al. This is an open access article distributed under the Creative Commons Attribution License, which permits unrestricted use, distribution, and reproduction in any medium, provided the original work is properly cited.

\begin{abstract}
Prefabricated box culvert is a new structure in road engineering, whose health is very important to road safety. The use of acoustic emission (AE) as a detection method and the use of other improved algorithms to evaluate the damage of prefabricated box culverts are still insufficient. In this paper, two kinds of prefabricated box culverts are tested and studied, and the damage process of the box culverts is analysed based on the AE parameters of the box culvert using the traditional fuzzy C-means method (FCM). In addition, an improved algorithm based on the combination of grid density and distance (G-DFCM) was proposed, which was simulated and applied to the AE data analysis of the prefabricated box culvert. The research results show that the application effect of the G-DFCM algorithm is good, which not only overcomes the shortcomings of the original algorithm but also improves the effectiveness of the algorithm. This work can provide a supplement to the damage identification of fabricated box culverts.
\end{abstract}

\section{Introduction}

As an important part of roadbed engineering, culverts are often buried under underground roadbeds as water passages or traffic interruptions. Common culvert structure types include box type, pipe type, and arch type. Box culverts can be divided into the integral cast-in-situ type and prefabricated assembled type according to the construction method. Integral cast-in-situ box culverts are suitable for various projects due to their high strength and rigidity and relatively low cost. Based on factorybased manufacturing, prefabricated assembled type box culverts have fast construction speed and stable quality and conform to the characteristics of green and ecological construction, which have attracted more and more attention in modern engineering construction methods. The research on the acoustic emission (AE) characteristics and damage identification methods of the integrally assembled box culvert and the four-component assembled box culvert in the prefabricated assembled box culvert is slightly insufficient.

Scholars around the world have carried out related research on the structure of prefabricated box culverts. Park et al. [1] simulated the influence of vehicle load and temperature load on the maximum tensile stress and cracking of the box culvert through the finite element method and proposed the optimal slab length and hinge position of different types of box culverts. Liu and Chen [2] made relevant studies on the design parameters, structural requirements, reinforcement types, and construction methods of prefabricated assembled culverts and provided a reference for the design of prefabricated box culverts.

Acoustic emission is a common method of non-destructive testing. Since its discovery, it has attracted more and more attention due to its convenience of detection $[3,4]$, and accuracy of the positioning $[5,6]$. Modern AE technology originated from the discovery of the Kaiser effect [7] and the Felicity effect [8]; then, some scholars continued to conduct in-depth research on the phenomenon of acoustic emission. Bhuiyan et al. [9] studied the AE waveforms of thin aerospace specimens, explained the correlation between the waveform evolution and the physical boundaries of cracks, and studied the growth mechanism of fatigue cracks. Madarshahian et al. [10] studied the problem of inverse 
source location in specific areas and proposed a method to determine the true arrival time based on probability theory.

Other scholars have also made relevant research on the damage identification method of determining the structure by AE signal. Krivosheev and Ivanov [11] proposed a trend statistical method for the AE signal of rock masses, described the statistical change criteria used to identify the flow, and gave the use of these criteria. Yang et al. [12] analysed the characteristics of the $\mathrm{AE}$ signal during the staged loading of concrete materials and used the activity coefficient ACT to indicate the activity of the $\mathrm{AE}$ activity. The results showed that the energy average exceeded $100 \mathrm{mV} \cdot \mathrm{ms}$ and the activity coefficient ACT was in the range of $20 \sim 70$ when the concrete material was destroyed.

It should be pointed out that the existing acoustic emission analysis is often used in ordinary concrete specimens, concrete beams, or other concrete specimens $[13,14]$, while the research on other types of models, especially box culvert and prefabricated box culvert, is slightly insufficient [15]. In addition, as a common method for processing $\mathrm{AE}$ data, the fuzzy C-means (FCM) clustering method has the inability to identify noise in processing data [16], and clustering is easy to fall into the local optimal situation [17]. Therefore, it is necessary to monitor, analyse damage process of the prefabricated assembled box culvert model, and optimize the damage identification process of the prefabricated assembled box culvert model. In this paper, aiming at the shortcomings of the existing literature in these aspects, the AE signals of the two prefabricated box culverts during the static load test loading and unloading process were collected through experiments. The damage process of the box culvert was analysed based on the test signals, and a damage identification algorithm based on FCM was proposed. This algorithm was compared and analysed with the traditional FCM method, statistical information grid-based (STING) method, and density-based spatial clustering of applications with noise (DBSCAN) method, in the meantime applying to the prefabricated box culvert scale model. The study can fill the problem of insufficient research on damage identification of prefabricated box culverts and provide a reference for the research process of damage identification of prefabricated box culverts.

\section{Materials and Methods}

2.1. Materials and Equipment. There are two types of common prefabricated box culverts: one is the integrally prefabricated culvert, and the other is the four-component prefabricated culvert. Integrally prefabricated culvert means that the culvert facade becomes a whole, and the assembly work only occurs between the culverts, while the fourcomponent prefabricated culvert is composed of the top plate, two side walls, and the cast-in-situ bottom plate. The assembly work of four-component prefabricated culvert is carried out not only between the culverts, but also between the various components in each culvert. In this experiment, based on the similar theorems [18-20] and the dimensional analysis, under the condition of ensuring that the prototype and the model had the same mechanical properties, the scale used in this experiment is $1: 4$. At the same time, to ensure that the model and the prototype had the same material properties, the concrete compressive strength was $40 \mathrm{MPa}$, which was the same as the prototype. The main reinforcement of the integrally assembled model was 20Ф6, and the stirrup was $87 \Phi 2$; for the four-component fabricated model, the main reinforcement was $20 \Phi 6$, and the stirrup was $80 \Phi 2$. The completed two box culvert model sizes are shown in Figures 1 and 2.

The SAEU2S acoustic emission system produced by Beijing Shenghua Testing Company was used in the test. The AE system was composed of an AE sensor, a preamplifier, and a computer. The AE sensor collected and converted the internal acoustic signal of the structure into an electrical signal and then transmitted it to the preamplifier. After being amplified by the preamplifier, the signal was transmitted to the computer for subsequent analysis work. The detailed technical parameters of the system are shown in Table 1. The HC-CK101 crack width observer produced by Beijing Haichuang Hi-Tech Company was used in the test. The detailed technical parameters of the instrument are shown in Table 2. Besides, the test loading equipment comes from the T-PMC microcomputer-controlled electro-hydraulic servo loading system produced by Changchun Xiaoxiu Metrology Technology Company. The parameters are shown in Table 3.

2.2. Test Scheme. In this test, a hydraulic Jack and an I-type beam were utilized for the four-point bending test. Three AE sensors were stuck on the culvert façade: one was on the middle span and the other two were near hinges of the culvert facade with scotch tape. Because the facade of the concrete box culvert was rough and uneven, the surface of the concrete was polished as smooth as possible with abrasive paper. In order to fix AE sensors well, Vaseline was used as a coupling agent to smear the contact surface between the sensor and the concrete. The schematic diagram of the loading device and $\mathrm{AE}$ sensors layout is shown in Figure 3.

The cyclic loading and unloading scheme was adopted in the test. According to the previous similar experiment experience of the research group and the conclusions of related documents $[16,21,22]$, the loading level interval was $3 \mathrm{kN}$, and each level of load was uniformly loaded and unloaded. For a whole cycle, the load was applied from 0 to the loading level in $200 \mathrm{~s}$, which was held in the next $300 \mathrm{~s}$. Then, it was unloaded to $0 \mathrm{kN}$ in $200 \mathrm{~s}$ and the interval between cycles was 1000 s. During the loading period and after completely unloading, the crack observation instrument was employed to observe the cracks. This loading system repeatedly loads and unloads the model until it was destroyed. The AE data and crack data of the top plate of the model were observed and recorded; subsequent analysis was performed.

\subsection{Current Status of Damage Identification Research.} Fuzzy C-means clustering (FCM) is a mathematical method based on the optimal solution of the function, through continuous iterative calculation, to separate the difficult-to- 


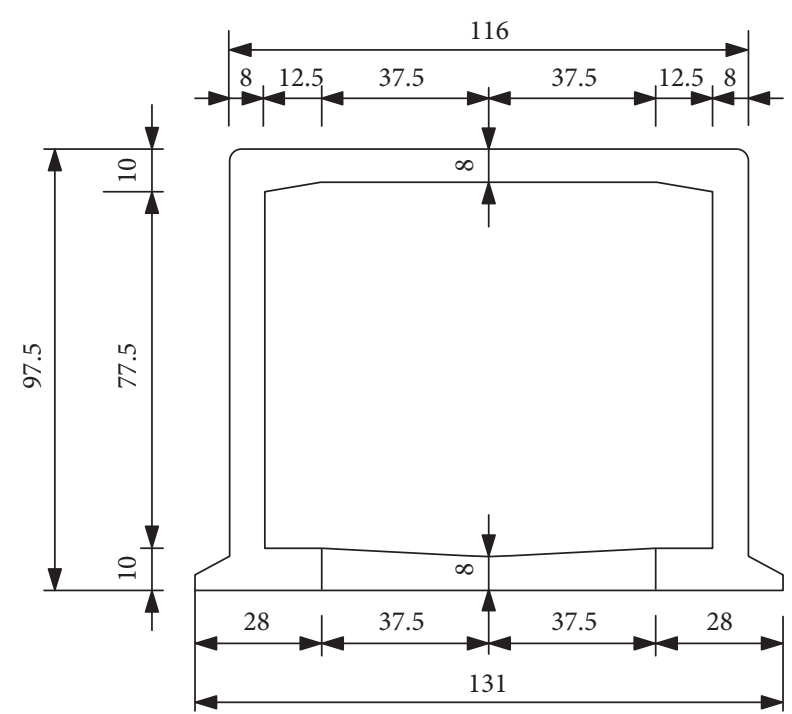

Figure 1: Dimension diagram of integrally assembled box culvert model.

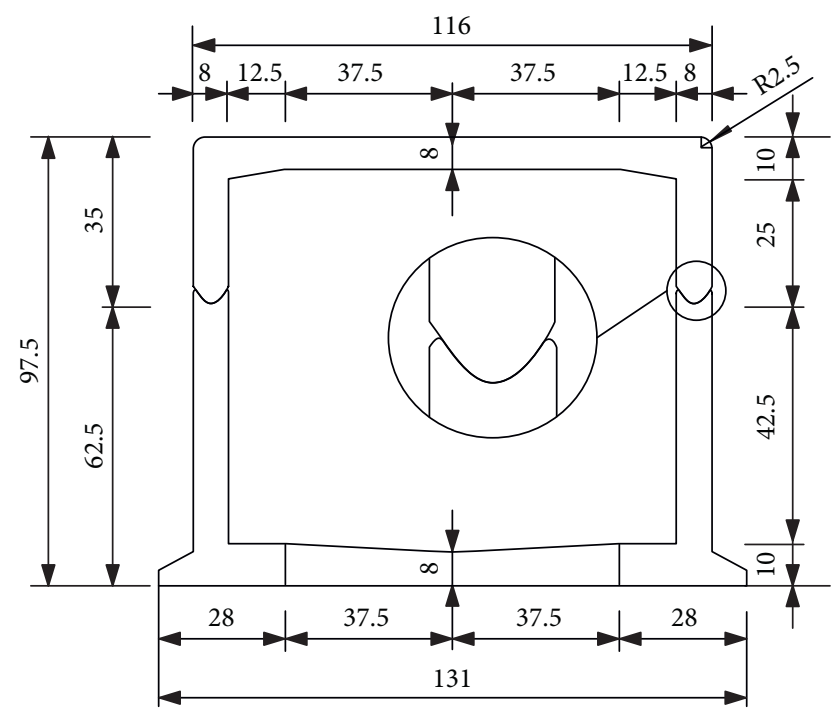

Figure 2: Dimensions of four-component fabricated box culvert model.

segment data set into visible and distinct data clusters. The process is usually achieved through the following 5 steps.

(1) The objective function is the sum of squared deviations, expressed by

$$
J(U, P)=\sum_{j=1}^{n} \sum_{i=1}^{c}\left[u_{i k}\right]^{m}\left(d_{i k}\right)^{2},
$$

where $u_{i k}$ is the membership degree of the $k$-th data point to the $i$-th cluster center, $m$ is smoothing parameter, and $\left(d_{i k}\right)^{2}$ is the Euclidean distance of the $k$-th data point to the $i$-th cluster center.
(2) The sample data is normalized to the $[0,1]$ interval to eliminate the difference in data scale. Normalization is expressed by

$$
x^{*}=\frac{x_{\max }-x}{x_{\max }-x_{\min }} .
$$

(3) Initialize the membership degree matrix; the membership degree matrix is expressed by

$$
\begin{aligned}
\sum_{i=1}^{t} u_{i k}=1, \quad 1 \leq k \leq c, \\
\sum_{n=1}^{c} u_{i k}>0, \quad 1 \leq i \leq t, \\
u_{i k} \geq 0,1 \leq i \leq t, 1 \leq n \leq c .
\end{aligned}
$$

(4) Enter the number of clusters, smoothing parameter, maximum number of iterations, and convergence criteria.

Under the constraints of equation (3), the minimum value of formula (1) is obtained by applying the Lagrange multiplier method to equation (1)and taking the derivative to obtain the elements of the membership matrix and cluster centers in each iteration through calculating. The cluster centers and elements of the membership matrix are expressed by

$$
\begin{aligned}
P_{i} & =\frac{\sum_{k=1}^{n}\left[u_{i}\left(x_{k}\right)\right]^{m} x_{k}}{\sum_{j=1}^{n}\left[u_{i}\left(x_{j}\right)\right]^{m}}, \quad i=1,2, \ldots, k, \\
u_{j t} & =\left[\sum_{i=1}^{c}\left(\frac{d_{j t}}{d_{i t}}\right)^{(2 / m-1)}\right]^{-1} .
\end{aligned}
$$

(5) Iteratively calculate the cluster centers and adjust the updated membership matrix until the convergence criterion is reached. At this time, the objective function reaches the minimum, and the final cluster center matrix and membership degree matrix are taken as the basis for drawing the clustering results.

As a commonly used soft clustering method, the traditional FCM method is often used to analyse the AE data of the structure. Based on the acoustic emission method and using the FCM method, Shao [23] monitored the damage process of steel tube constrained reinforced concrete columns and obtained the damage type and cracking mode of the structure. Zhao et al. [24] used principal component analysis (PCA) and FCM to cluster the AE signals collected during the torsion test of the 3D braided composite shaft. The study found the material failure mode and mechanism by analysing the structural damage. Zhao and Zhou [25] used $\mathrm{AE}$ and FCM methods to evaluate the damage process of carbon/glass fiber reinforced hybrid composite materials and obtained the characteristics of the three damage modes of the material, which provided a reference for the health monitoring of the material. But due to the random generation of its initial membership matrix, it was easy to cause a 
TABLe 1: Technical parameters of acoustic emission system.

\begin{tabular}{lcccc}
\hline Name & Model & Test frequency range $(\mathrm{kHz})$ & Noise minimum threshold $(\mathrm{dB})$ & Maximum signal amplitude $(\mathrm{dB})$ \\
\hline Acoustic emission system & SAEU2S & $3 \sim 2000$ & 10 & 100
\end{tabular}

TABLE 2: Technical parameters of creak observation equipment.

\begin{tabular}{lcccc}
\hline Name & Model & Magnification & Range $(\mathrm{mm})$ & Minimum indexing $(\mathrm{mm})$ \\
\hline Crack width observer & HC-CK101 & 40 & $0 \sim 2$ & 0.02 \\
\hline
\end{tabular}

TABle 3: Technical parameters of microcomputer-controlled electro-hydraulic servo loading system.

\begin{tabular}{lcc}
\hline Name & Model & Range (kN) \\
\hline Microcomputer-controlled electro-hydraulic servo loading system & T-PMC & $0 \sim 100$ \\
\hline
\end{tabular}

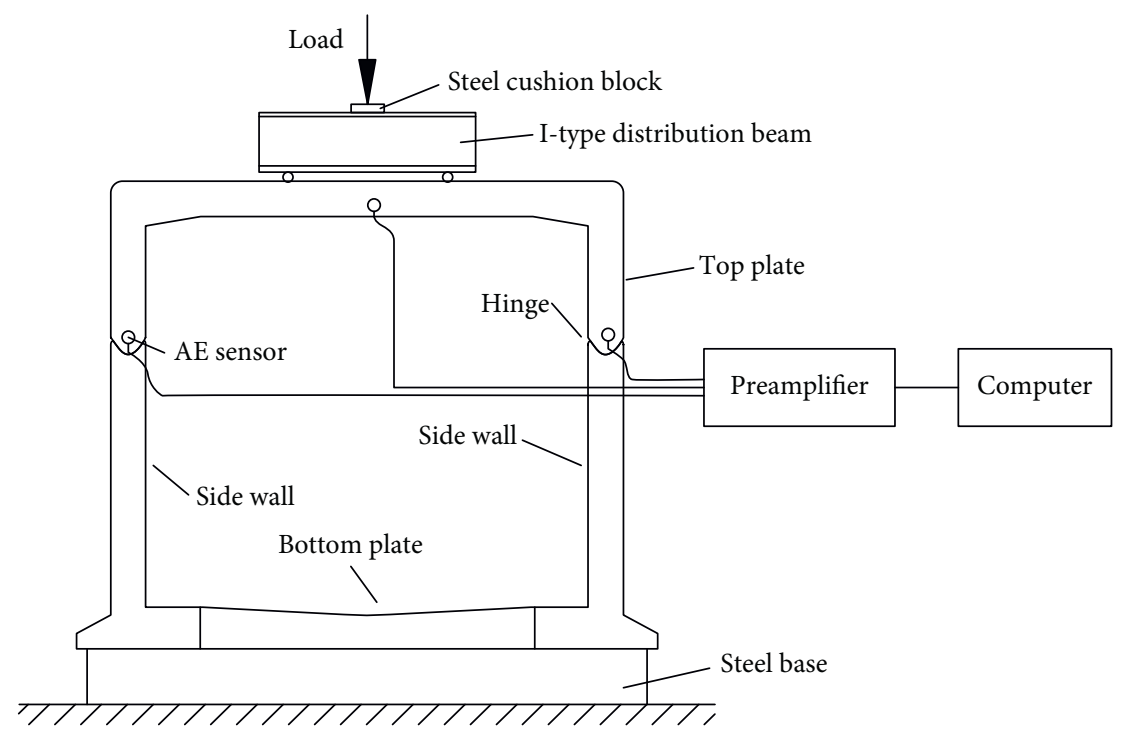

FIgURE 3: Diagram of loading device and AE sensors layout.

local optimal situation [26]. To solve this problem, Liang and Xue [27] used a method that combines an improved artificial bee colony algorithm and KFCM algorithm to improve the problem. The results showed that, compared to the IABCGFCM algorithm, the algorithm could effectively improve the cluster validity index.

The basic idea of the STING method is to grid the data space and analyse the data with space as the basic unit. The advantage is that the calculation speed is faster, but the disadvantage is that the space complexity is high when the mapping path is long and the dimensions are uneven [28].

The density-based algorithm represented by the DBSCAN algorithm has been applied in many fields by scholars due to its effectiveness in filtering noise and flexibility in processing data [29, 30], but it was more sensitive to input parameters [31]. The density peak clustering algorithm proposed by Rodriguez and Laio [32] was based on the spatial hierarchical relationship and provides two methods for different users. It was extremely flexible, but its complexity was high, and it had poor adaptability to high-dimensional data [33].
Aiming at the shortcomings of the above three algorithms and drawing on their advantages and inspired by the above algorithms, this paper proposes a grid-based fuzzy $\mathrm{C}$-means clustering analysis method based on the combination of density and distance (G-DFCM).

2.4. G-DFCM Clustering Method. The G-DFCM algorithm aims at solving the fuzzy $\mathrm{C}$-means clustering easy to fall into the local optimal and cannot identify the noise situation. First, select the first clustering center grid according to the peak density, calculate the membership grid matrix, and use it as the initial membership matrix to replace the matrix which is the first step to initialize the membership randomly in the normal fuzzy C-means algorithm, to solve the occurrence of local optimal conditions. Secondly, for the case that the original algorithm cannot identify noise, the relative grid average density parameter is proposed to distinguish the noise data in the original data. Finally, a two-step method is used to reduce the sample space and optimize the original objective function. The optimized objective function is based 
on the grid. The membership degree of the grid is substituted for the degree of membership of the point, and the Euclidean distance of the point is replaced by the grid distance, and the relative grid average density parameter is introduced to reduce the number of iterations and reduce the calculation time. It is convenient for the objective function to converge to the minimum value as soon as possible. The following describes the foundation and detailed steps of the algorithm.

\subsubsection{G-DFCM Algorithm Foundation.}

Definition 1. Grid density:

$$
R_{i}=\frac{\sum_{j=1}^{k} \rho_{j}}{k},
$$

where $R_{i}$ is the grid density of the $i$ grid, $k$ is the amount of data in the $i$ grid, and $\rho_{j}$ is the local density of the point, which can be calculated according to

$$
\rho_{j}=\sum_{j=1}^{n} \chi\left(d_{i j}-d_{c}\right)
$$

where $\rho_{j}$ is the local density of point $j, n$ is the amount of data, $\chi(x)$ is the indicator function, $\chi(x)=\left\{\begin{array}{l}1, x<0 \\ 0, \text { others }\end{array}, d_{i j}\right.$ is the Euclidean distance of point $j$ to the center $i$, and $d_{c}$ is the cutoff distance, which is defined by the user. When defining the local density, keep it greater than the minimum point value.

Definition 2. Relative grid average density:

$$
R_{i j}=\frac{R_{j}}{R_{i}} .
$$

Definition 3. G-DFCM algorithm objective function:

$$
J(U, V)=\sum_{i=1}^{c} \sum_{j=1}^{n}\left[u_{i j}\right]^{m}\left(d_{i j}\right)^{2} R_{i j} .
$$

Use the Lagrange multiplier method to find the partial derivative of the objective function:

$$
\begin{aligned}
u_{i j} & =\left[\frac{\left(d_{i j}\right)^{2} R_{i j}}{\sum_{k=1}^{c}\left(d_{k j}\right)^{2} R_{k j}}\right]^{-(1 / m-1)}, \\
C_{i} & =\frac{\sum_{j=1}^{n}\left[u_{i j}\right]^{m} R_{i j} x_{j}}{\sum_{j=1}^{n}\left[u_{i j}\right]^{m} R_{i j}}
\end{aligned}
$$

where $u_{i j}$ is the membership degree of grid $j$ relative to the center grid of $i, R_{i j}$ is the average density of the relative grid, $d_{i j}$ is the Euclidean distance of grid $j$ relative to the center grid of $i$, and $C_{i}$ is the $i$-th cluster center grid.

\subsubsection{The Specific Operation Steps of the G-DFCM Algorithm.} The specific operation steps of the G-DFCM algorithm are as follows:
Data normalization: use normalization methods to adjust the data to $[0,1]$ to eliminate the difference in data point scale.

Data gridization: grid the region, and assign the data to the corresponding grid according to its location.

Calculate the parameters of the points in the grid: calculate the local density parameters of all data according to equation (7).

Datapoint classification: according to the density calculation result of equation (6), the effective point and the noise point are distinguished, and the noise point is removed from the original data after the noise point is output to facilitate the subsequent steps.

Screening of grid density: screen all grids, and use the average density of all points in the grid as the grid density of the grid.

Calculation of grid average density: calculate the relative grid average density according to equation (8).

Enter the number of clusters, the maximum number of iterations, smoothing parameter, and convergence criterion.

Calculate the initial membership matrix: take the highest grid density as the clustering center, and calculate the membership matrix once according to equation (9), and use it as the initial membership matrix to replace the randomly generated membership in the original algorithm membership grid matrix.

Continue to iteratively calculate the membership degree matrix and the clustering center matrix according to equations (10) and (11) until the objective function equation (9) reaches the minimum value.

Output the final membership degree matrix, cluster center matrix, objective function value, iteration calculation times, running time, and noise points.

2.5. G-DFCM Simulation Experiment. The performance of the G-DFCM method was tested. The test environment was built as a platform: Core i7-4710HQ $(2.5 \mathrm{GHz})$ processor, $8 \mathrm{~GB}$ memory, and Windows 10 operating system. This algorithm was developed and tested in Matlab R2018a. The test data set used the open data sets Iris [34] and Glass [35] in the UCI data set. The relevant information of the two data sets is shown in Table 4. Since the two data sets do not contain noise data, the Balance-scale data set and the $\mathrm{Cmc}$ data set with the same dimensions were manually introduced as noise data, and the relevant information of the two data sets is shown in Tables 4 and 5. The test aimed to compare the effectiveness of noise discrimination, convergence speed, and clustering effectiveness with the normal FCM algorithm, STING algorithm, and DBSCAN algorithm through this algorithm.

When calculating with G-DFCM, the following parameters need to be entered: number of clusters, cutoff distance, the minimum number of points, and three common data maximum iterations, smoothing parameter, and convergence criterion. Among them, the first three data sets 
TABLE 4: Related information of the two data sets.

\begin{tabular}{lccc}
\hline Data set & The amount of data & Dimension & The amount of clusters \\
\hline Iris & 150 & 4 & 3 \\
Glass & 214 & 9 & 6 \\
\hline
\end{tabular}

TABLE 5: Related information of the two noise data sets introduced.

\begin{tabular}{lccc}
\hline Data set & The amount of original data & The amount of data introduced & Dimension \\
\hline Balance-scale & 625 & 30 & 4 \\
Cmc & 1473 & 30 & 9 \\
\hline
\end{tabular}

have a greater impact on the clustering speed and accuracy, and different values should be selected for different data sets, and the last three data sets can generally use common values. The value assignment of each parameter is shown in Table 6.

\section{Results and Discussion}

3.1. Parameter Analysis of Acoustic Emission in the Model Test. When a load is applied to the structure, the AE parameters generated by the structure will change drastically. Through the model test, the AE data of the integrally assembled box culvert and the four-component assembled box culvert were collected, including amplitude, ringing count, duration, rising count, rising time, energy, etc. Among them, amplitude, ringing count, and energy are the most commonly used analysis parameters. The amplitude represents the maximum amplitude of the AE signal waveform, which directly reflects the strength of the signal. The ringing count represents the number of oscillations in the $\mathrm{AE}$ signal waveform that exceed the threshold, and it also reflects the strength and frequency of the signal. Amplitude and ringing count are both important indicators to measure the intensity of AE. Energy represents the amount of energy released by changes in the energy level of the stress wave and reflects the relative strength of the signal. Due to the particularity of the ringing count, the ringing count was used as the representative parameter to analyse the $\mathrm{AE}$ parameters. In the subsequent analysis, three common parameters are also selected as clustering data.

Figures 4 and 5 are graphs of the ringing count and cumulative ringing count of the two prefabricated box culvert models over time. Table 7 is crack data of fourcomponent assembly box culvert in model test.

$N_{\mathrm{i}}$ was used to represent the ringing count of the integrally assembled box culvert, and $N_{\mathrm{f}}$ was used to represent the ringing count of the four-component assembly box culvert. The following can be known from the figure:

(1) In the initial loading stage of the integrally assembled box culvert (the first five loading stages), the structural acoustic emission phenomenon was not obvious, and occasionally a slightly stronger acoustic emission activity occurred. At this time, the highest value of the ringing count was $N_{i, \max 1}=597$, and the cumulative ringing count rose slowly. However, the initial loading of the four-component assembly box culvert was shorter (the first two loading stages), and the highest ringing count was $N_{f, \max 1}=1023$. Combined with the crack observation instrument to observe the two box culverts, no cracks occurred. Therefore, this stage of the two box culverts was the initial structural compaction and internal slippage of the structure, and the internal damage of the structure was in the cumulative stage. Occasionally, a slightly stronger acoustic emission activity was the release of energy when the internal pores were closed under pressure or the internal structure of the structure slips.

(2) In the mid-loading period of the integrally prefabricated box culvert (the sixth and seventh loading stages), the structural acoustic emission phenomenon was very violent and peaks were generated, the highest ringing count was $N_{i}$, $\max 2=973$, and the cumulative ringing count was suddenly increased. Combined with the crack observation instrument, two cracks were generated, which were located in the middle of the top plate and a quarter of the span, whose length was $4.0 \mathrm{~cm}$ and $3.5 \mathrm{~cm}$, respectively, and width was $0.28 \mathrm{~mm}$ and $0.14 \mathrm{~mm}$, respectively. The loading period of the four-component assembly box culvert was slightly longer (the third to sixth loading stages), the maximum ringing count was $N_{f, \max 2}=1527$, and the cumulative ringing count was rising steadily. Combined with the observation of the crack observer, one crack was generated, which was located at the middle of the top plate, whose length was $6.8 \mathrm{~cm}$ and width was $0.3 \mathrm{~mm}$. Therefore, in the mid-loading period of the two box culverts, the internal damage accumulation limit was reached, and the process of releasing accumulated energy in the form of cracks began.

(3) At the end of the loading stage (the eighth and ninth loading stage) of the integrally prefabricated box culvert, the acoustic emission activity produced a secondary peak, accompanied by frequent acoustic emission phenomena. Combined with the observation of the crack observation instrument, two new cracks were generated, located between the right quarter span and the middle span and another quarter of the span, whose length was $2.9 \mathrm{~cm}$ and 
TABle 6: Parameter value assignment table.

\begin{tabular}{lcc}
\hline Name of parameters & Data set & Value assignment \\
\hline Number of clusters & Iris & 4 \\
& Glass & 9 \\
Cutoff distance & Iris & 0.4 \\
& Glass & 1.0 \\
Minimum number of points & Iris & 30 \\
\hline Maximum iterations & Glass & 30 \\
Smoothing parameter & & 100 \\
Convergence criterion & & 22 \\
\hline
\end{tabular}

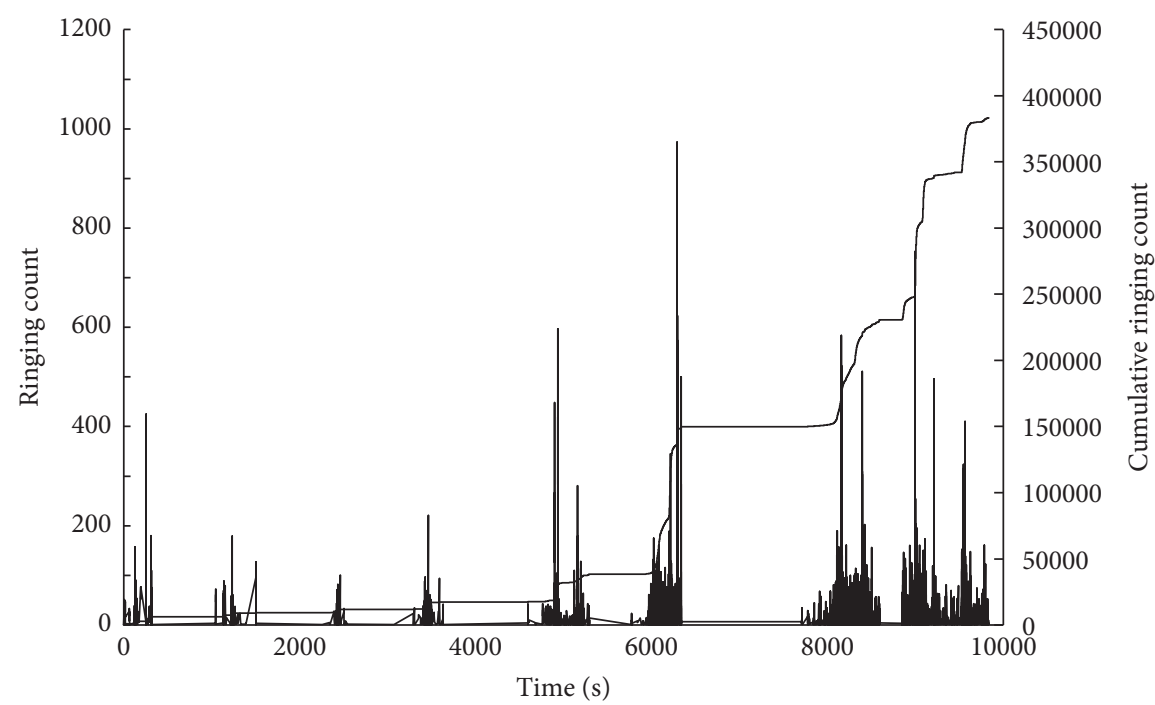

Figure 4: The change diagram of integrally assembled box ringing count and cumulative ringing count over time.

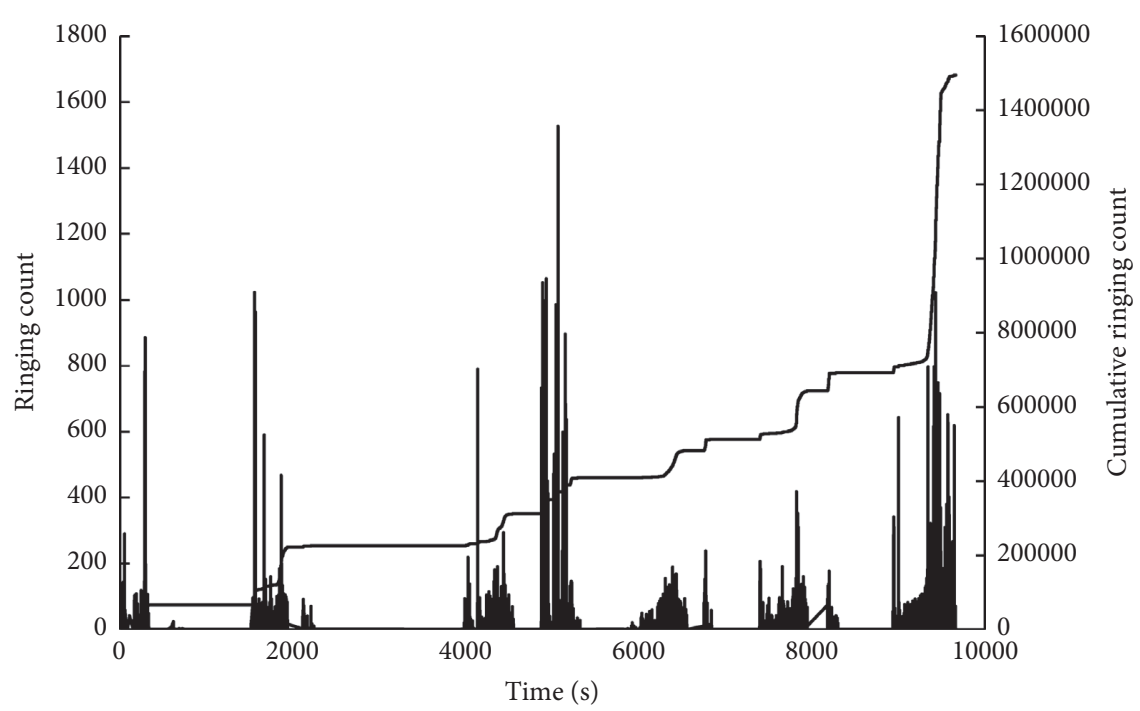

FIGURE 5: Four-component assembly box ringing count and cumulative ringing count change with time.

$3.6 \mathrm{~cm}$, respectively, and width was $0.09 \mathrm{~mm}$ and $0.18 \mathrm{~mm}$, respectively. The loading end of the fourcomponent assembly box culvert was slightly shorter (the seventh loading stage) and was also accompanied by frequent ringing counting signals and two cracks were generated in the right quarter span and 
TABLE 7: Crack data of four-component assembly box culvert in model test.

\begin{tabular}{|c|c|c|c|c|c|}
\hline Load level $(\mathrm{kN})$ & Loading/unloading & Crack number & Crack starting point $(\mathrm{cm})$ & Crack width $(\mathrm{mm})$ & Crack length $(\mathrm{cm})$ \\
\hline 3.0 & Loading & - & - & - & - \\
\hline 6.0 & Loading & - & - & - & - \\
\hline \multirow{2}{*}{9.0} & Loading & 1 & $(63.8,0)$ & 0.30 & 6.8 \\
\hline & Unloading & 1 & $(63.8,0)$ & 0.04 & 6.8 \\
\hline \multirow{4}{*}{12.0} & \multirow{2}{*}{ Loading } & 1 & $(63.8,0)$ & 0.48 & 8.0 \\
\hline & & 2 & $(37.0,0)$ & 0.44 & 6.4 \\
\hline & \multirow{2}{*}{ Unloading } & 1 & $(63.8,0)$ & 0.18 & 8.0 \\
\hline & & 2 & $(37.0,0)$ & 0.30 & 6.4 \\
\hline \multirow{4}{*}{15.0} & \multirow{2}{*}{ Loading } & 1 & $(63.8,0)$ & 1.26 & 8.0 \\
\hline & & 2 & $(37.0,0)$ & 0.54 & 6.4 \\
\hline & \multirow{2}{*}{ Unloading } & 1 & $(63.8,0)$ & 0.59 & 8.0 \\
\hline & & 2 & $(37.0,0)$ & 0.28 & 6.4 \\
\hline \multirow{6}{*}{18.0} & \multirow{3}{*}{ Loading } & 1 & $(63.8,0)$ & 1.50 & 8.0 \\
\hline & & 2 & $(37.0,0)$ & 0.58 & 6.4 \\
\hline & & 3 & $(84.0,0)$ & 0.05 & 7.5 \\
\hline & \multirow{3}{*}{ Unloading } & 1 & $(63.8,0)$ & 0.72 & 8.0 \\
\hline & & 2 & $(37.0,0)$ & 0.28 & 6.4 \\
\hline & & 3 & $(84.0,0)$ & 0.03 & 7.5 \\
\hline \multirow{6}{*}{21.0} & \multirow{3}{*}{ Loading } & 1 & $(63.8,0)$ & 9.00 & 8.0 \\
\hline & & 2 & $(37.0,0)$ & 2.26 & 6.4 \\
\hline & & 3 & $(84.0,0)$ & 1.70 & 7.5 \\
\hline & \multirow{3}{*}{ Unloading } & 1 & $(63.8,0)$ & 5.10 & 8.0 \\
\hline & & 2 & $(37.0,0)$ & 1.08 & 6.4 \\
\hline & & 3 & $(84.0,0)$ & 0.73 & 7.5 \\
\hline
\end{tabular}

The origin of the coordinates is set at the imaginary intersection point between the lower edge of the top plate and the outer edge of the side wall.

left quarter span, whose length was $6.4 \mathrm{~cm}$ and $7.5 \mathrm{~cm}$, respectively, and width was $0.08 \mathrm{~mm}$ and $0.05 \mathrm{~mm}$, respectively. Therefore, at the end of loading of the two box culverts, cracks and deformations continued to be used to release the accumulated energy to the full, and the structure tended to be destroyed until the bearing capacity was completely lost. Other acoustic emission signals showed a tendency to change synchronously with the ring count.

(4) In terms of cumulative ringing count performance, the overall prefabricated box culvert model generally presented a "three-stage" upward trend, and the two inflection points were located at $66.67 \%$ and $77.78 \%$ of the ultimate load, respectively. The four-member prefabricated box culvert generally presents a "twostage" upward trend, and the only inflection point was near the ultimate load. This showed that the overall prefabricated box culvert was more sensitive to load than the four-member prefabricated box culvert. As long as the damage accumulates to a certain degree, energy would be released through cracks appearance. The crack data of the fourmember box culvert model is shown in Table 4 .

(5) The two box culvert models from the early to midloading stage were both in the transition period from the elastic stage to the plastic stage. The difference was that the integrally prefabricated box culvert had a longer elastic phase (the first five loading phases), and the four-member prefabricated box culvert had a longer plastic phase (third to sixth loading phases). Therefore, corresponding to the actual structure, the integrally assembled box culvert structure had a longer elastic stage and could work for a long time without cracks under the low load level, so the performance would be more excellent. Under the action of great load level, because the four-member prefabricated box culvert had a longer plastic phase, it could continue to work for a longer time with cracks. For larger loads, due to the stronger ultimate bearing capacity of the integrally assembled box culvert, the integrally assembled box culvert was more reliable under extreme conditions.

3.2. FCM Analysis of Acoustic Emission in the Model Test. Although the use of AE parameter analysis can preliminarily characterize the damage of the two box culverts, because this method uses single factor analysis in the reanalysis process and is mixed with some subjective wishes, it is easy to draw one-sided conclusions [36, 37]. For making a distinction among the damage stages more reasonably, the fuzzy C-means clustering method is used to comprehensively analyse the collected three acoustic emission representative signals, namely, amplitude (dB), ringing count, and energy $(\mathrm{mV} \cdot \mu \mathrm{s})$; these parameters can reflect the meaning represented by the AE signal from different angles. The relevant parameters given in this analysis are as follows: the number of clusters is 3 , the smoothing parameter is commonly used as 2 [38], the maximum number of iterations is 100 , and the convergence criterion is $1 E-5$. Among them, the 
smoothness index affects the clustering mode. The closer the parameter is to 1 , the closer the clustering result is to the traditional hard clustering method. The smoothness index is generally of a common value 2 . Convergence criteria and the maximum number of iterations affect the tolerance of the clustering results; the larger the maximum number of iterations or the smaller the convergence criterion value, the higher the clustering accuracy and the longer the calculating time. The convergence criteria and maximum number of iterations are generally of a common value $1 E-5$ and 100 , respectively. Substitute the acoustic emission data and four parameters into equations (1) (5) until the change value of the calculation result of equation (1) reaches the convergence criterion before reaching the maximum number of iterations.

The clustering results after FCM calculation are shown in Figures 6 and 7. The following can be known from the figure:

(1) For low-energy (less than $1 E 4 \mathrm{mV} \cdot \mu \mathrm{s}$ [39]) data, the results of the two prefabricated culverts were similar: cluster 1 had the characteristics of low amplitude and low ringing count, and the amplitude range was located at $40.1 \sim 45.9 \mathrm{~dB}$ and $40.1 \sim 46.1 \mathrm{~dB}$, and the ring count interval was 1 425 and 1 964, respectively. Observing with the crack observer, no macroscopic cracks were generated, and the influence of laboratory environment noise was taken into account, which meant it was related to the accumulated damage inside the model or the noise signal that cannot be filtered. Compared with cluster 1, cluster 2 had a higher amplitude and ringing count. The amplitude ranges were $42.4 \sim 55.3 \mathrm{~dB}$ and $43.3 \sim 56.4 \mathrm{~dB}$, and the ring count ranges were $1 \sim 720$ and 1 1079. There are no macroscopic cracks measured by the crack observer, so this was related to the relative slippage inside the model and the initiation and formation of micro-cracks. Compared with cluster 2, the amplitude and ringing count of cluster 3 increased again. The amplitude ranges were $47.2 \sim 99.6 \mathrm{~dB}$ and $52.2 \sim 100 \mathrm{~dB}$, and the ringing count ranges were 7 973 and 3 1527. There were still no macroscopic cracks after observation with the crack observer, but the environmental noise would not reach such a high level and would not have such a significant impact on the structure, so this was related to the development of micro-cracks inside the model.

(2) For high-energy data (higher than $1 E 4 \mathrm{mV} \cdot \mu \mathrm{s}$ ), there was a big difference between the two types of fabricated culverts: the overall fabricated culvert had high-energy AE signals while simultaneously having a high amplitude and high ringing counts. The amplitude range was higher than $99.0 \mathrm{~dB}$ and the ringing count range was higher than 612 . At the same time, combined with the crack observer, it observed the cracks on the lower edge of the upper roof plate and found a crack in the middle of the span with a width of $0.50 \mathrm{~mm}$ and a length of $5.8 \mathrm{~cm}$. A crack was found in a quarter span with a width of $0.14 \mathrm{~mm}$ and

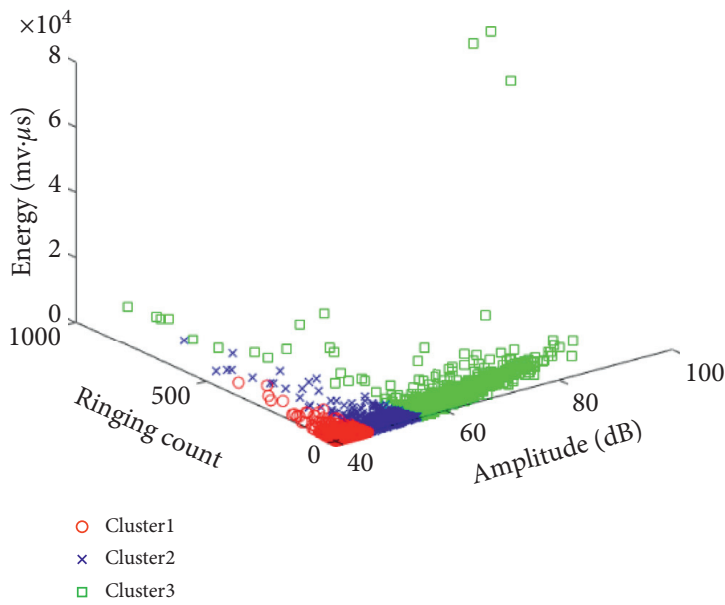

FIGURE 6: The direct clustering results of the whole assembled box culvert model.

a length of $4.8 \mathrm{~mm}$, so this was related to the sudden release after the cumulative damage, which directly produces visible cracks; it indicated that the destruction of the integrally fabricated culvert was relatively sudden, and the precursor features were not obvious, while the four-component assembled culvert model had a wider range of high-energy signal values. It not only had a large number of data points in the high-amplitude area, but also had a certain number of data points in the other two groups. This was related to the increasing cumulative damage, but the slow generation of macroscopic cracks, indicating that the failure process of the fourmember assembly culvert was relatively slow and the precursor characteristics were obvious.

3.3. Results of G-DFCM Simulation Experiment. According to the above-mentioned G-DFCM method to calculate the results of the simulation experiment, the experimental results are as follows: the noise calculation results are shown in Table 8 and the number of convergences and operation time in the calculation process are shown in Table 9 and Figures 8 and 9 .

Analyse the accuracy of the G-DFCM clustering algorithm. Since the XB index considers the geometric structure information and membership degree of the data set at the same time [40], the XB index is used to verify the clustering effectiveness of the above method, and the XB index can be expressed by the following equation [41]:

$$
X B^{(-)}=\frac{\sum_{i=1}^{K} \sum_{j=1}^{n} \mu_{i j}^{m} d\left(x_{j}, v_{i}\right)}{n \times \min _{i \neq j} d\left(v_{i}, v_{j}\right)},
$$

where (-) indicates that the index is a minimum index; that is, the smaller the value, the higher the clustering effectiveness. 


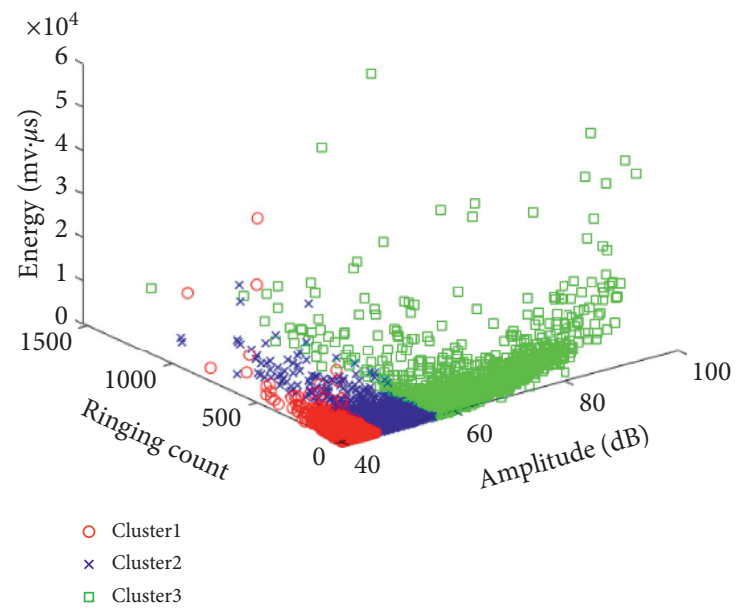

Figure 7: The direct clustering results of four-component assembled box culvert model.

TABLE 8: Data set noise calculation results.

\begin{tabular}{|c|c|c|c|c|c|}
\hline $\begin{array}{l}\text { Calculation } \\
\text { method }\end{array}$ & Data set & $\begin{array}{l}\text { The amount of total } \\
\text { data }\end{array}$ & $\begin{array}{c}\text { The amount of noise point } \\
\text { calculation }\end{array}$ & $\begin{array}{c}\text { The amount of noise accurate } \\
\text { calculation }\end{array}$ & $\begin{array}{c}\text { Accuracy } \\
(\%)\end{array}$ \\
\hline \multirow[t]{2}{*}{ G-DFCM } & $\begin{array}{l}\text { Iris + Balance- } \\
\text { scale }\end{array}$ & 180 & 30 & 30 & 100.00 \\
\hline & Glass + Cmc & 244 & 32 & 30 & 93.75 \\
\hline \multirow{2}{*}{ DBSCAN } & $\begin{array}{l}\text { Iris + Balance- } \\
\text { scale }\end{array}$ & 180 & 39 & 30 & 76.92 \\
\hline & Glass + Cmc & 244 & 32 & 32 & 52.63 \\
\hline \multirow[t]{2}{*}{ FCM } & $\begin{array}{c}\text { Iris + Balance- } \\
\text { scale }\end{array}$ & 180 & $-^{1}$ & - & - \\
\hline & Glass + Cmc & 244 & 一 & - & - \\
\hline \multirow[t]{2}{*}{ STING } & $\begin{array}{c}\text { Iris + Balance- } \\
\text { scale }\end{array}$ & 180 & $-^{2}$ & - & - \\
\hline & Glass + Cmc & 244 & - & - & - \\
\hline
\end{tabular}

${ }^{1}$ FCM algorithm cannot identify noise. ${ }^{2}$ The STING algorithm is not suitable for high-dimensional data.

TABle 9: Comparison of data set calculation process.

\begin{tabular}{lccc}
\hline Calculation method & Data set & Number of convergence iterations & Operation time (s) \\
\hline \multirow{2}{*}{ G-DFCM } & Iris + Balance-scale & 16 & 0.368 \\
& Glass + Cmc & 35 & 0.363 \\
\hline \multirow{2}{*}{ DBSCAN } & Iris + Balance-scale & - & 1.030 \\
& Glass + Cmc & - & 0.995 \\
\multirow{2}{*}{ FCM } & Iris + Balance-scale & 16 & 0.309 \\
& Glass + Cmc & 43 & 0.286 \\
\multirow{2}{*}{ STING } & Iris + Balance-scale & $-{ }^{1}$ & - \\
& Glass + Cmc & - & - \\
\hline
\end{tabular}

${ }^{1}$ The STING algorithm is not suitable for high-dimensional data.

Table 10 and Figure 10 show the XB index values of the two fuzzy algorithms.

From Table 8 and Figure 10, it can be concluded that the G-DFCM algorithm not only identifies noise points but also improves the effectiveness of clustering through almost the same or lower number of iterations, while only increasing a small amount of computing time.
3.4. G-DFCM Analysis of Acoustic Emission in Model Test. The G-DFCM algorithm is used to analyse the AE data of the test integrated box culvert. The clustering results are shown in Figure 11.

Figure 11 indicates that the clustering result of acoustic emission data using the G-DFCM algorithm has clearer boundaries and more obvious differences between clusters. 


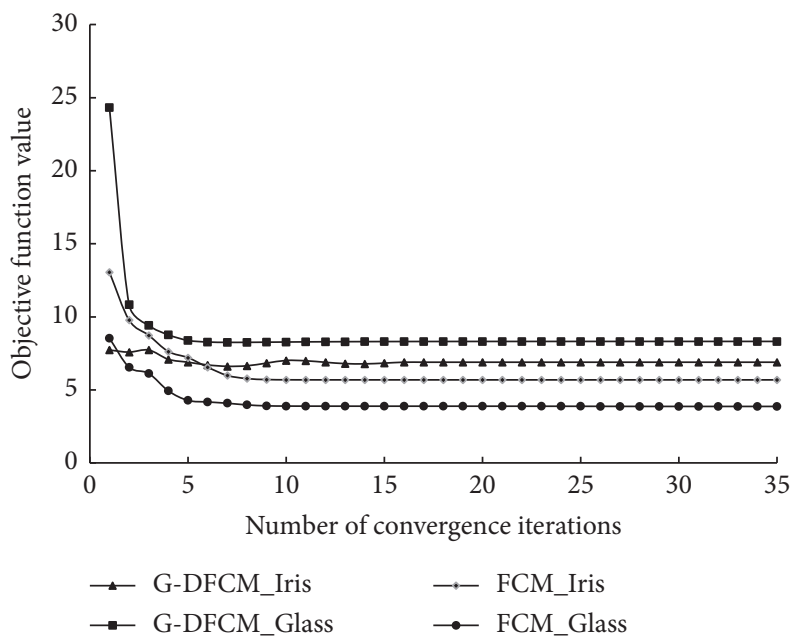

Figure 8: Comparison of iteration times.

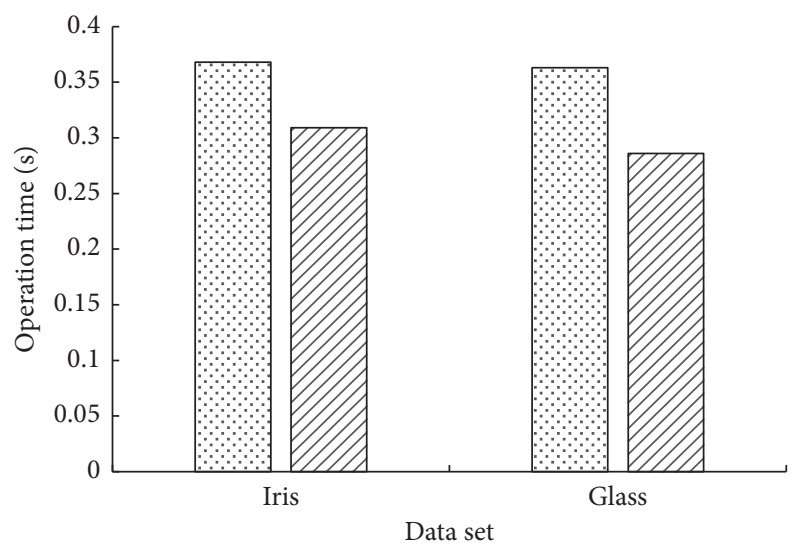

a G-DFCM

$\square$ FCM

FIgURE 9: Comparison of operation times.

TABle 10: Data set XB index comparison.

\begin{tabular}{lcc}
\hline & & Data set \\
Calculation method & Iris & Glass \\
\hline G-DFCM & 0.023 & 0.057 \\
FCM & 0.108 & 0.143 \\
\hline
\end{tabular}

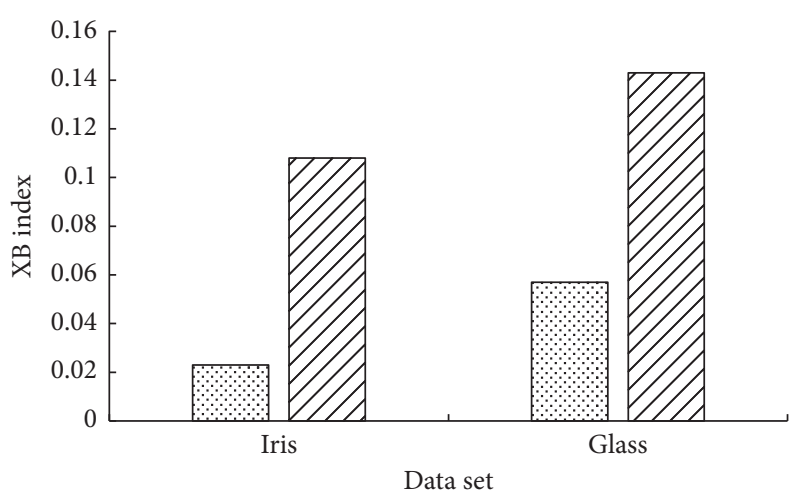

$\because \mathrm{G}-\mathrm{DFCM}$

$\square \mathrm{FCM}$

Figure 10: XB index comparison. 


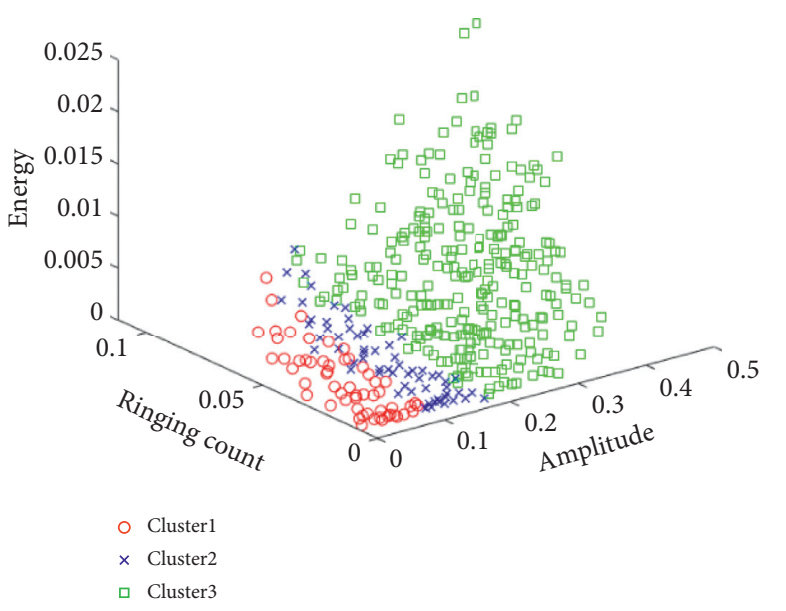

Figure 11: The G-DFCM method clustering results of the acoustic emission of the integrally assembled box culvert.

This is mainly due to the higher clustering effectiveness of the algorithm.

\section{Conclusions}

Aiming at the deficiencies in the research on the structure of the prefabricated box culvert and the damage identification method, this paper had made and tested the scaled model of the prefabricated box culvert; the $\mathrm{AE}$ data during the test were collected and analysed; a grid-based fuzzy C-means clustering analysis method was proposed based on the combination of density and distance (G-DFCM), and the algorithm was simulated to verify its effect, and it was applied to the damage identification process of the assembled box culvert. Through the analysis of the research results in the experiment, the main conclusions of this paper are as follows:

(1) The failure process of both culvert models includes three stages, namely, the accumulation of internal damage and internal structural slippage, the formation and development of micro-cracks, and the formation and development of macro-cracks. But the difference is that the destruction process of the integrally fabricated culvert is more sudden and the stage is more obvious; the failure process of the fourmember fabricated box culvert is slower and the precursors are obvious.

(2) For low-energy signals, the acoustic emission amplitude range of $40 \sim 46 \mathrm{~dB}$ corresponds to the accumulation of structural internal damage; amplitude range of $43 \sim 56 \mathrm{~dB}$ corresponds to the internal structure slip; amplitude range of $49 \sim 99.8 \mathrm{~dB}$ corresponds to the formation and development of structural micro-cracks. For high-energy signals, they are often accompanied by high amplitude and high ringing count (amplitude interval higher than $99.0 \mathrm{~dB}$, ringing count interval higher than 612). Such signals usually correspond to structural macroscopic cracks.
(3) Compared with the FCM algorithm, the G-DFCM algorithm improves the clustering effectiveness by $69.4 \%$ and can identify noise while the calculation time and the number of iterations are similar, and has the ability to identify the noise. The G-DFCM algorithm is used to cluster the $\mathrm{AE}$ data of the prefabricated box culvert. It can be found that this method can make the clustering boundary clearer and the clustering effect more obvious.

\section{Data Availability}

The Iris, Balance-scale, Glass, and $\mathrm{Cmc}$ data used to support the findings of this study have been deposited at http:// archive.ics.uci.edu/ml/index.php. Additionally, raw data generated during the study are available from the corresponding author upon request.

\section{Conflicts of Interest}

The authors declare that there are no conflicts of interest regarding the publication of this paper.

\section{Acknowledgments}

This work was funded by the National Natural Science Foundation of China (Project no. 51978309), the Transportation Technology Program of Jilin Province of China (Grant no. 2018-1-9), the Education Department's "13th Five-Year" Science and Technology Program of Jilin Province (Grant no. JJKH20190015KJ), the Special Funding for Basic Scientific Research Operation Fees of Central Universities, the Scientific and Technological Developing Scheme Program of Jilin Province (Grant no. 20200403157SF), and the Transportation Technology Program of Jilin Province of China (Grant no. 2018ZDGC-16).

\section{References}

[1] J.-Y. Park, D.-S. Sohn, J.-H. Lee, and J.-H. Jeong, "A study on joint position at concrete pavement with box culverts," Journal of the Korean Society of Road Engineers, vol. 14, no. 2, pp. 45-53, 2012.

[2] S. Liu and M. Chen, "Design and construction of prefabricated cover passage and culvert," Highway, vol. 2002, no. 7, pp. 94-95, 2002.

[3] Q. Zhang and Y. Zhang, "Research status and prospect of concrete acoustic emission technology," Applied Mechanics and Materials, vol. 170-173, pp. 470-473, 2012.

[4] D. Soulioti, N. M. Barkoula, A. Paipetis, T. E. Matikas, T. Shiotani, and D. G. Aggelis, "Acoustic emission behavior of steel fibre reinforced concrete under bending," Construction and Building Materials, vol. 23, no. 12, pp. 3532-3536, 2009.

[5] A. Olszewska, "Location of partial discharge sources in oil transformer with the use of analysis of acoustic emission signals in various frequency bands," Przeglad Elektrotechniczny, vol. 86, no. 11B, pp. 63-65, 2010.

[6] Q. Wang and X. Liu, "Acoustic emission sensors circular array for concrete structure damaging source DOA estimation," Structural Health Monitoring 2011: Condition-based Maintenance and Intelligent Structures, vol. 2, no. 1, pp. 2189-2194, 2013. 
[7] P. Ziehl, Monitoring of the Bonnet Carre Spillway Bridge during Extreme Overload, Department of Civil and Environmental Engineering, Tulane University, New Orleans, LA, USA, 2003.

[8] R. S. Gostautas, G. Ramirez, R. J. Peterman, and D. Meggers, "Acoustic emission monitoring and analysis of glass fiberreinforced composites bridge decks," Journal of Bridge Engineering, vol. 10, no. 6, pp. 713-721, 2005.

[9] M. Y. Bhuiyan, B. Lin, and V. Giurgiutiu, "Acoustic emission sensor effect and waveform evolution during fatigue crack growth in thin metallic plate," Journal of Intelligent Material Systems and Structures, vol. 2017, no. 1, pp. 1276-1284, 2017.

[10] R. Madarshahian, P. Ziehl, and J. M. Caicedo, "Acoustic emission Bayesian source location: onset time challenge," Mechanical Systems and Signal Processing, vol. 123, no. 123, pp. 483-495, 2019.

[11] I. A. Krivosheev and G. A. Ivanov, "Statistical method for processing acoustic emission signals in rock mass," Russian Journal of Nondestructive Testing, vol. 38, no. 2, pp. 127-129, 2002.

[12] Y. Yang, J. Liu, R. Xue, and Y. Gao, "Analysis of acoustic emission characteristics in the process of graded loading of concrete materials," Journal of Agricultural University of Hebei, vol. 41, no. 1, pp. 100-105, 2008.

[13] C.-L. Wang, Z. Chen, Z.-F. Liao et al., "Experimental investigation on predicting precursory changes in entropy for dominant frequency of rockburst," Journal of Central South University, vol. 27, no. 10, pp. 2834-2848, 2020.

[14] S. W. Hu, J. Lu, and X. Zhong, "Study on characteristics of acoustic emission property in the normal concrete fracture test," Advanced Materials Research, vol. 189-193, pp. 1117-1121, 2011.

[15] R. Birgul, F. M. W. Al-shammari, and I. O. Yaman, "Acoustic emission evaluation of concrete culverts," Research in Nondestructive Evaluation, vol. 15, no. 4, pp. 191-208, 2004.

[16] X. Xu, Y. Zhang, and X. Li, "Research on damage identification method of reinforced concrete beams based on acoustic emission and depth confidence network," Journal of Building Structures, vol. 39, no. S2, pp. 400-407, 2008.

[17] A. Chen and H. Yan, "An improved fuzzy C-means clustering for brain MR images segmentation," Journal of Medical Imaging and Health Informatics, vol. 11, no. 2, pp. 386-390, 2021.

[18] L. A. Zadeh, "Similarity relations and fuzzy orderings," Journal of Information Science, vol. 3, no. 2, pp. 177-200, 1971.

[19] F. Ma, Z. Li, R. Xue, and G. Luo, "NIOS model materials and their application in geomechanical similar model test," Journal of Hydroelectric Engineering, vol. 2004, no. 1, pp. 48-51, 2004.

[20] N. S. Kim, J. H. Lee, and S. P. Chang, “An equivalent multiphase similitude law for pseudodynamic test on small-scale RC models: verification tests," Journal of the Earthquake Engineering Society of Korea, vol. 7, no. 6, pp. 834-846, 2004.

[21] S. H. Kim, B. S. Shin, and I. J. Park, "Model test on concrete placement method of tunnel lining due to tunnel size," Journal of Korean Tunnellinge Underground Space Association, vol. 11, no. 3, pp. 213-221, 2009.

[22] R. M. Bennett, S. M. Wood, E. C. Drumm, and N. R. Rainwater, "Vertical loads on concrete box culverts under high embankments," Journal of Bridge Engineering, vol. 10, no. 6, pp. 643-649, 2005.

[23] J. Shao, Investigation on Damage Mechanisms of Civil Structures Based on Acoustic Emission Technique, Dalian University of Technology, Dalian, China, 2017.
[24] G. Zhao, L. Zhang, C. Tang, W. Hao, and Y. Luo, "Clustering of AE signals collected during torsional tests of $3 \mathrm{D}$ braiding composite shafts using PCA and FCM," Composites Part B: Engineering, vol. 161, no. 1, pp. 547-554, 2019.

[25] W.-z. Zhao and W. Zhou, "Cluster analysis of acoustic emission signals and tensile properties of carbon/glass fiberreinforced hybrid composites," Structural Health Monitoring, vol. 18, no. 5-6, pp. 1686-1697, 2019.

[26] Z. Han, D. Li, and J. Zhao, "Image segmentation algorithm based on improved genetic fuzzy clustering and level set," Computer Engineering and Design, vol. 40, no. 5, pp. 13901393, 2019.

[27] B. Liang and H. Xue, "Kernel fuzzy C-means clustering based on improved artificial bee colony algorithm," Journal of Computer Applications, vol. 34, no. 9, pp. 2600-2604, 2017.

[28] A. Amini, T. Y. Wah, and H. Saboohi, "On density-based data streams clustering algorithms: a survey," Journal of Computer Science and Technology, vol. 29, no. 1, pp. 116-141, 2014.

[29] K. M. Jones and M. Lacy, "Measuring the clustering around normal and dust-obscured quasars at 2 in the spitzer extragalactic representative volume survey," in Proceedings of the American Astronomical Society Meeting, Boston, MA, USA, June 2014.

[30] S.-J. Horng, M.-Y. Su, Y.-H. Chen et al., "A novel intrusion detection system based on hierarchical clustering and support vector machines," Expert Systems with Applications, vol. 38, no. 1, pp. 306-313, 2011.

[31] Z. Li and Y. Zhang, "Analysis and evaluation of cluster analysis algorithm," Electronic Technology and Software Engineering, vol. 153, no. 7, p. 172, 2019.

[32] A. Rodriguez and A. Laio, "Clustering by fast search and find of density peaks," Science, vol. 344, no. 6191, pp. 1492-1496, 2014.

[33] Y. Chen, L. Shen, and C. Zhong, "Survey on density peak clustering algorithm," Journal of Computer Research and Development, vol. 57, no. 2, pp. 378-394, 2020.

[34] F. Liu, Y. Liang, and T. Hou, "Research and improvement of fuzzy C-harmonic mean algorithm on unbalanced data," Journal of Jilin University (Engineering and Technology Edition), 2020.

[35] A. Seal, A. Karlekar, and O. Krejcar, "Fuzzy c-means clustering using Jeffreys-divergence based similarity measure," Applied Soft Computing, vol. 88, pp. 1-11, 2020.

[36] W. Zhao, Composite Deformation Damage Monitoring and Acoustic Emission Characteristic Signal Clustering Analysis, Hebei University, Baoding, China, 2018.

[37] R. L. Cannon, J. V. Dave, and J. C. Bezdek, "Efficient implementation of the fuzzy c-means clustering algorithms," IEEE Transactions on Pattern Analysis \& Machine Intelligence, vol. 8, no. 2, pp. 248-255, 2009.

[38] A. A. A. Ahmed and A. A. H. B. Assem, "Classification of damage in self-consolidating rubberized concrete using acoustic emission intensity analysis," Ultrasonics, vol. 100, pp. 1-10, 2020.

[39] M. Wang, Study on Flexural Fracture Resistance and Acoustic Attenuation Characteristics of Basalt Fiber Concrete Based on Acoustic Emission Parameters, Jilin University, Changchun, China, 2017.

[40] K. Zhou, S. Yang, and S. Ding, "Summary of clustering validity research," Systems Engineering Theory and Practice, vol. 34, no. 9, pp. 2417-2431, 2014.

[41] X. L. Xie and G. Beni, "A validity measure for fuzzy clustering," IEEE Transactions on Pattern Analysis and Machine Intelligence, vol. 13, no. 8, pp. 841-847, 1991. 